\title{
CELL CULTURE AS THE MOST CERTAIN WAY OF DIAGNOSIS IN RABIES INFECTION
}

\author{
Ariyani Noviantari ${ }^{1}$, Khariri ${ }^{1}$ \\ ${ }^{1}$ Centre for Research and Development of Biomedical and Basic Health Technology, \\ National Institute of Health Research and Development (NIHRD), Ministry of Health, Republic of Indonesia \\ 1ariyani.noviantari@gmail.com
}

\begin{abstract}
Rabies is a zoonotic disease that causes progressive and fatal inflammation of the brain and spinal cord. This disease is still widespread in the world and is a social and economic burden in many countries. Rabies is estimated to cause 60.000 human deaths annually in over 150 countries, with $95 \%$ of cases occurring in Africa and Asia. Several countries in Southeast Asia, including Indonesia, have become one of the endemic areas for rabies. The diagnosis of rabies infection in animals and humans can be made by histopathology, virus cultivation, serology, and virus antigen detection This paper discusses cell culture as a method in the diagnosis of rabies. This paper is a literature review through a literature search in scientific journals and research reports that explains the various studies on the isolation of Rabies virus in cell culture, cell types used, and the technique in diagnosing Rabies infection in cell culture. The diagnosis of rabies can be made by neuroblastoma cells, BHK-21 cell lines, HEK-293 cell lines, and others. It can be concluded that the diagnosis of Rabies virus can be done on several cell lines and needs to be followed by other tests. The nature of rabies disease dictates that laboratory tests be standardized, rapid, sensitive, specific, economical, and reliable.
\end{abstract}

Keyword: animal, cell culture, humans, Rabies, zoonotic disease

\section{Introduction}

Rabies is a zoonotic disease that causes progressive and fatal inflammation of the brain and spinal cord. This disease is still widespread in the world and is a social and economic burden in many countries. Rabies is estimated to cause 60.000 human deaths annually in over 150 countries, with $95 \%$ of cases occurring in Africa and Asia. Several countries in Southeast Asia, including Indonesia, have become one of the endemic areas for rabies $(1,2)$.

In Indonesia, there are reportedly 10 provinces as rabies-free areas out of 34 provinces in Indonesia, namely Bangka Belitung, Riau Islands, DKI Jakarta, DI Yogyakarta, East Java, West Nusa Tenggara, West Papua, Papua and West Kalimantan. Provinces that are included in the top 5 ranking of Rabies cases from 2009-2013 are Bali, East Nusa Tenggara, and North Sumatra. (3).

Rabies attacks warm-blooded animals, including humans and as a vector or reservoir are dogs, cats and monkeys. Animal rabies is characterized by 3 forms of clinical symptoms, namely calm, furious and atypical (4).

The rabies virus is transmitted through a rabid-positive animal bite through saliva and passed to the nerve endings are injured through a bite or lick wound on the skin wound, and through the axons to the central nervous system (CNS) so produces acute encephalo-myelitis. This inflammation occurs all over brain and spinal cord The virus is not only present in the CNS, but also in the salivary glands, tear glands, suprarenal glands and pancreas, but in rabies transmission, only the salivary glands take hold a very important role (5). 
The diagnosis of rabies infection in animals and humans can be made by histopathology, virus cultivation, serology, and virus antigen detection. There are three reference techniques are recognised by both WHO and OIE, namely fluorescent antibody test (FAT), Rabies tissue culture infection test (RTCIT) and mouse inoculation test (MIT) (6). the isolation followed by viral replication assay may be used in isolates from different reservoirs which enable an effective amplification of the wild type virus strains (7).

Laboratory diagnosis and surveillance for animal and human rabies are severely constrained in much of the developing world where rabies is endemic. The most confirmatory test among these several diagnostic methods is virus isolation (VI) by inoculating to cell cultures (8). This paper discusses cell culture as a method in the diagnosis of rabies.

\section{Methods}

This paper is a literature review through a literature search in scientific journals and research reports that explains the various studies on the isolation of Rabies virus in cell culture, the technique in diagnosing Rabies infection, and cell types used.

\section{Result}

Rabies is a the fatal zoonotic disease caused by a virus neurotropics of the genus Lyssavirus belonging to the family Rhabdoviridae, order Mononegavirales, (9). Lyssaviruses have a 12$\mathrm{kb}$ non-segmented RNA genome of negative polarity that encodes five viral proteins ( $3^{\prime}$ to $\left.5^{\prime}\right)$ : a nucleoprotein $(\mathrm{N})$, a phosphoprotein $(\mathrm{P})$, a matrix protein $(\mathrm{M})$, a glycoprotein $(\mathrm{G})$ and an RNA-dependent RNA polymerase (or large protein, L). The Rabies virus genome composed of $\mathrm{N}, \mathrm{P}$ and $\mathrm{L}$ proteins, which forms ribonucleoprotein complex that helps in multiplication of virus in the cytoplasm of host cells (5).

\section{Discussion}

\section{Technique in Diagnosing Rabies Infection}

Mani et. al. explain explained the basic techniques are described in the WHO publication Laboratory Techniques in Rabies and the OIE Manual of Diagnostic Tests and Vaccines for Terrestrial Animals (10) :
1. Direct Microscopy: Histological Identification of Characteristic Cell Lesions. Infected neuronal cells reveal aggregates of viral particles "Negri bodies" which are intracytoplasmic inclusion bodies specific to rabies encephalitis, demonstrated by histological tests (Seller'sTechnique) on smears taken from various areas of the brain. Negri bodies vary in size from as small as $3 \mu \mathrm{m}$ to as large as $30 \mu \mathrm{m}$ and are generally circular or oval and deeply eosinophilic with characteristic basophilic granules, often arranged in the form of a rosette, within the eosinophilic matrix.

\section{Antigen Virus}

a. Fluorescent Antibody Technique (FAT).

The fluorescent antibody technique (FAT) test is the gold standard test for rabies diagnosis. The principle of FAT is when it is on preparations touch originating from the hippocampus or medulla oblongata is reacted with antibodies conjugated with the substrate Fluorescein Isothiocyanate produces a green glow light youth as a result of a complex antigen-antibody reaction. FAT test can also result in false-negative results even though they are not common [3]. Hence, due to the greater significant impact of the laboratory results, small quantities of the virus in very weakly FAT positive samples are confirmed by the mouse inoculation test (MIT) (11).

b. Rapid Rabies Enzyme Immunodiagnosis (RREID)

This technique is based on capturing rabies $\mathrm{N}$ protein in a brain homogenate by a polyclonal or monoclonal anti-N antibody coated on the solid phase. Subsequently, the captured antigen is detected by adding peroxidase onjugated monoclonal or polyclonal antibody raised in a different species or even better by the addition of biotinylated $\mathrm{N}$ antibody followed by streptavidin peroxidase and colour development with ophenylenediamine dihydrochloride (OPD) and hydrogen peroxide. In various studies, the test is found to be as sensitive and specific as FAT.

\section{Virus Isolation}

a. Mouse Inoculation Test (MIT)

Mice Inoculation Test (MIT), which is to inoculate a brain test sample or inoculum to mice through intra cerebral with the observation period for 28 days. The isadvantage of MIT is the long interval before a diagnosis can be made 
since the inoculated mice need to be kept under observation for 28 days as some wild viruses may have a very long incubation period.

b. Rapid Tissue Culture Infection Test (RTCT)

As compared to MIT, virus isolation in cell culture is fast and results can be given in 24-48 hours. The cell linesmost suitable for virus isolation are of neural origin and the most commonly used cell line is themurine neuroblastoma cell line Neuro-2a. Other cell lines which are used but may not be as sensitive as Neuro-2a include chicken embryo-related (CER) and baby hamster kidney (BHK 21) cells.

\section{Antibodies Test}

a. The Mouse Neutralization Test (MNT)

The widely used virus neutralization test in mice (MNT) developed in 1935 by Webster and Dawson is no longer recommended by theWHO or OIE.

b. Rapid Fluorescent Focus Inhibition Test (RFFIT)

The rapid fluorescent focus inhibition test (RFFIT) is routinely used in the United States to measure rabies virus neutralizing antibodies (rVNA). The RFFIT is one of the most widely used substitutes to the Mouse Neutralization Test (MNT) and is a rapid test that requires only 20 hours for completion and is slightly more sensitive than the MNT (12).

c. Fluorescence Antibody Virus Neutralization Test (FAVN)

The Fluorescent Antibody Virus neutralization (FAVN) test was adapted from the original RFFIT and thoroughly evaluated against both recommended methods such as RFFIT and MNT.16 The results showed a very good agreement between the FAVN test, the RFFIT and the MNT. This method, using 96-well microplates instead of 8-well labtek chambers, was mainly intended to provide a reliable reading (13).

\section{Cell Line Types Used}

The diagnosis of rabies can be made by neuroblastoma cells, BHK-21 cell lines, HEK293 cell lines, and others. It can be concluded that the diagnosis of Rabies virus can be done on several cell lines and needs to be followed by other tests.

The Third Virtual Conference ICATD
1. Neuroblastoma cells

Neuro 2A (N2a) is a mouse neural crestderived cell line (14). Murine neuroblastoma cells (e.g. NA C1300) are more susceptible to field isolates of lyssavirus than other cell lines tested. Virus isolation in neuroblastoma cell culture is at least as efficient as animal inoculation, especially for small quantities of virus. Cell culture isolation also reduces the time required for diagnosis, from 10-21 days with the mouse inoculation test to only 2-4 days. If the conditions are not optimal, however, such as decomposed brain, falsenegative results may be obtained. When cell culture facilities or molecular methods are not available, animal inoculation can be used. If a rapid answer is required, suckling mice $(<3$ days old) are preferred to weanling or adult mice, because they are more susceptible than older animals. The observation period may be shortened by inoculation of sufficient mice to enable sequential killing and examination of brains by the FAT, starting 4 days postinoculation (15).

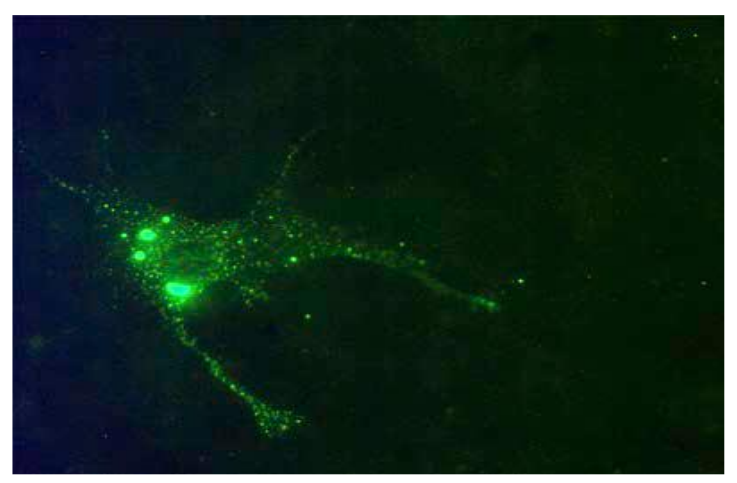

Figure 1. Rabies virus-infected neuroblastoma cells under fluorescence microscopy, labeled with a rabies antinucleocapsid FITC - conjugated antibody. The presence of bright green fluorescent inclusions in the cytoplasm indicates rabies virus infection (magnification $\times 400)(16)$.

2. Human Embryonic Kidney (HEK) 293 cell line

The HEK-293 cell line is as sensitive as the Neuro-2a cell line for the rapid isolation of rabies virus and may serve as an alternative cell line for rabies diagnosis and future research. The human embryonic kidney cell 
line HEK-293 is known to express several neuronal proteins and is believed to be of neuronal origin (17).

Human embryonic kidney cell line HEK293 was generated by transformation of human embryonic kidney cell cultures with sheared adenovirus 5 DNA. This continuous cell line has been used for transfection studies in cell biology. As this cell line expresses several neuronal proteins, including muscarinic acetylcholine receptors. the origin of this cell line is now believed to be from embryonic neural cells. Keeping this in view, we wanted to know if this cell line is susceptible to a neurotropic virus such as rabies virus and whether this cell line could be used for rapid isolation of rabies viruses to confirm the diagnosis of rabies in animals and humans (17).

The number of fluorescing cells was similar between Neuro-2a and HEK-293 cells. The sensitivity of the HEK-293 cell line was found to be equal to that of the Neuro-2a cell line, as both cells showed fluorescing cells (6).

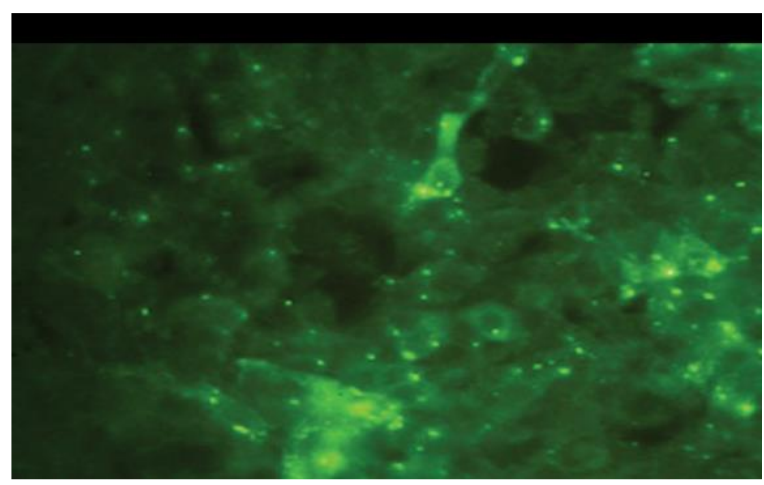

Figure 2. Virus isolation in HEK 293 cell line stained with fluorescent antibody technique (FAT) (10)

3. Baby Hamster Kidney (BHK) 21 cell line

The first attempt for the isolation of rabies virus was performed on baby hamster kidney cell line (BHK-21), but the results were not the expected ones, with variable success rates and inferior sensitivity when compared to the MIT (6).

Virus Isolation (VI) in BHK-21 cells that grow faster and are much easier to maintain, does represent an adequate alternative for MIT as a confirmatory test for rabies diagnostic in bovine specimens, yielding reliable results in reduced time. (14).

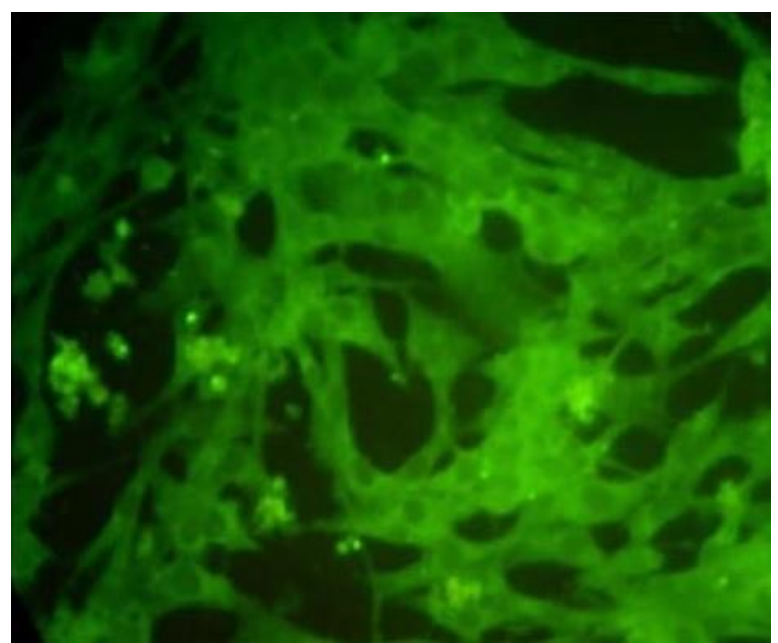

Figure 3. virus isolation in BHK-21 cells. The cells were infected with street virus strains of rabies virus and stained by fluorescent antibody test (17).

\section{Conclusion}

The nature of rabies disease dictates that laboratory tests be standardized, rapid, sensitive, specific, economical, and reliable.

\section{Acknowledgment}

We would like to thank to Head of Centre for Research and Development of Biomedical and Basic Health Technology, National Institute of Health Research and Development (NIHRD), Ministry of Health Republic of Indonesia.

\section{References}

[1] Fooks AR, Banyard AC, Horton DL, Johnson N, Mcelhinney LM, Jackson AC. Current status of rabies and prospects for elimination. Lancet [Internet]. 2014;6736(13):1-11. Available from: http://dx.doi.org/10.1016/S01406736(13)62707-5

[2] WHO. Rabies Rabies: A neglected zoonotic disease [Internet]. World Health Organization. 2020 [cited 2020 Sep 10]. p. 1-2. Available from: https://www.who.int/rabies/home_more/en/

[3] Situasi dan Analisis Rabies. InfoDATIN [Internet]. 2014;1-6. Available from: https://www.kemkes.go.id/resources/downlo $\mathrm{ad} /$ pusdatin/infodatin/infodatin-rabies.pdf 
[4] Yousaf MZ, Qasim M, Zia S, Khan R, Ashfaq UA, Khan S. Rabies molecular virology, diagnosis, prevention and treatment. Virol J. 2012;9(50):1-5.

[5] Singh R, Singh KP, Cherian S, Saminathan M, Kapoor S, Reddy GBM, et al. Rabies epidemiology, pathogenesis, public health concerns and advances in diagnosis and control: a comprehensive review. Vet Q [Internet]. 2017;37(1):212-51. Available from: https://doi.org/10.1080/01652176.2017.134 3516

[6] Dascalu M, Servat A, Velescu E, Tanase O. TWO DIFFERENT SYSTEMS FOR THE ISOLATION OF RABIES VIRUS IN CELL CULTURES. Bulg J Vet Med. 2017;20(Suppl. 1):219-27.

[7] Pattern D, Cell N, Costa BA, Fuoco NL, Chaves LB, Rodrigues AC, et al. Rabies lyssavirus Isolates from Brazilian Different Reservoirs Species Present Virology \& Mycology Rabies lyssavirus Isolates from Brazilian Different Reservoirs Species Present Distinct Pattern of Propagation in N2a Cell. 2016;(February 2018):1-6.

[8] Yang D, Shin E, Oh Y, Lee K, Lee C, Kim $\mathrm{S}$, et al. Comparison of four diagnostic methods for detecting rabies viruses circulating in Korea. J Vet Sci. 2012;13(1):43-8.

[9] Amarasinghe GK, Ayllón MA, Bào Y, Basler CF, Bavari S. Taxonomy of the order Mononegavirales : update 2019. Arch Virol. 2019;(May):1-14.

[10] Mani RS, Madhusudana SN. Laboratory Diagnosis of Human Rabies: Recent Advances. Sci World J. 2013;1-10.

[11] Sasikalaveni A, Tirumurugaan KG, Manoharan S, Raj GD, Kumanan K. Co- culture: A quick approach for isolation of street rabies virus in murine neuroblastoma cells. Vet World. 2015;8:636-9.

[12] Smith TG, Gilbert AT. Comparison of a Micro-Neutralization Test with the Rapid Fluorescent Focus Inhibition Test for Measuring Rabies Virus Neutralizing Antibodies. Trop Med Infect Dis. 2017;2(24):1-6.

[13] Cliquet F, Wasniewski M. The Fluorescent Antibody Virus Neutralization Test [Internet]. Second Edition. Vol. 2, Current Laboratory Techniques in Rabies Diagnosis, Research and Prevention. Elsevier Inc.; 2015. 217-232 p. Available from: http://dx.doi.org/10.1016/B978-0-12801919-1.00018-X

[14] Tremblay RG, Sikorska M, Sandhu JK, Lanthier P, Ribecco-Lutkiewicz M, BaniYaghoub M. Differentiation of N2a cells into dopamine neurons . Differentiation of mouse Neuro 2A cells into dopamine neurons. J Neurosci Methods. 2010;186:607.

[15] WHO Expert Consultation on Rabies Third report. Geneva; 2018.

[16] Dacheux L, Bourhy H. Virus Isolation in Cell Culture: The Rabies Tissue Culture Infection Test. In: Current Laboratory Techniques in Rabies Diagnosis, Research and Prevention. 2015. p. 25-31.

[17] Madhusudana SN, Sundaramoorthy S, Ullas PT. Utility of human embryonic kidney cell line HEK-293 for rapid isolation of fixed and street rabies viruses: comparison with Neuro-2a and BHK-21 cell lines. Int J Infect Dis [Internet]. 2010;14(12):e1067-71. Available

from: http://dx.doi.org/10.1016/j.ijid.2010.07.004 